\title{
Construção da Carreira Docente em Educação Física: Escolhas, Trajetórias e Perspectivas
}

\author{
Alexandra Folle* \\ Gelcemar Oliveira Farias** \\ Juliano Daniel Boscatto*** \\ Juarez Vieira do Nascimento****
}

\begin{abstract}
Resumo: O objetivo desta investigação foi analisar a história de vida de professores de Educação Física, procurando identificar as escolhas, as perspectivas e as trajetórias vivenciadas. Participaram do estudo quatro professores que se encontram em diferentes fases da carreira docente (entrada, consolidação, diversificação e estabilização). Na recolha das informações foi utilizada a entrevista semi-estruturada e a técnica da narrativa foi empregada na análise dos dados. As evidências do estudo confirmam que docentes, mesmo com formações realizadas em momentos distintos e que atuam em contextos diferenciados, apresentam pontos comuns nas suas trajetórias profissionais, respeitadas as especificidades da história pessoal de cada professor.
\end{abstract}

Palavras-chave: Papel profissional. Docentes. Educação Física. Mobilidade Ocupacional. Estudos de casos.

\section{INTRODUÇÃO}

A carreira docente é permeada por desafios, dilemas e conquistas que repercutem no processo de como o professor percebe-se e sentese no ambiente de trabalho, na busca da realização pessoal e profissional. Tardif (2000), Huberman (2000) e Valle (2006) concebem a carreira docente como um processo de socialização e incorporação na atividade profissional, de modo a apresentar variações de acordo com o tempo e a função a ser desempenhada.

* Mestranda em Educação Física UFSC. Bolsista CAPES. Florianópolis, SC, Brasil. E-mail: afolle_12@hotmail.com

** Doutoranda em Educação Física UFSC. Professora do Curso de Educação Física da ULBRA. E-mail: gelfarias@pop.com.br

*** Mestrando em Educação Física UFSC. Florianópolis, SC, Brasil. E-mail: jubismo@yahoo.com.br ****Doutor em Ciências do Desporto. Professor do Curso de Educação Física da UFSC. Florianópolis, SC, Brasil. E-mail: juarezvn@cds.ufsc.br 
Enquanto Tardif (2000) compreende a carreira como uma prática e rotina institucionalizada no campo do trabalho, identificada com o processo de socialização profissional, Huberman (2000) destaca que a carreira é marcada por vários acontecimentos que se tornam marcantes na trajetória do docente, compreendendo arranques, descontinuidades e becos sem saída que possibilitam a mudança de percurso. Por outro lado, Valle (2006) aponta que a carreira docente pode ser percebida a partir de duas vertentes contraditórias: uma como mediadora para o desempenho de diferentes funções docentes e outra como a inserção na carreira propriamente dita.

Shigunov, Farias e Nascimento (2002) argumentam que é no decorrer da carreira docente que se adquire as experiências necessárias para o desenvolvimento e a melhoria da prática pedagógica. Todavia, o impacto inicial enfrentado pelo professor ao ingressar na carreira, ou seja, a transição de estudante para profissional, de conceitos acadêmicos para aplicabilidade prática, de rotinas em grupo para a sustentação e posicionamento individual, suscitam determinados questionamentos. Algumas investigações que abordam esta temática (SILVA, 1997; BENITES; SOUZA NETO, 2005; MARTÍNEZ, 2000) têm procurado estabelecer relação entre a formação inicial e a inserção no mercado de trabalho. No entanto, os investigadores têm observado que, ao ingressar na profissão, o docente assume responsabilidades profissionais cada vez mais crescentes, para as quais muitas vezes não se sente devidamente preparado.

Ao conceberem que a formação do professor inicia-se pelo processo de escolha de ser docente, Prado (2007), Benites e Souza Neto (2005) apontam que o indivíduo que opta pela profissão Educação Física normalmente é jovem e está cercado de incertezas quanto ao seu futuro. Essa escolha pode gerar confusões e inseguranças frente a uma decisão que pode ou não ser acertada e/ou concretizada.

Diante deste quadro, alguns questionamentos surgem sobre as diferentes escolhas, trajetórias e expectativas do professor, quais sejam: O professor desde que inserido na carreira docente mantém uma trajetória linear das suas ações? Os professores apresentam preocupações comuns durante o seu percurso profissional? As expectativas

Movimento, Porto Alegre, v. 15, n. 01, p. 25-49, janeiro/março de 2009. 
profissionais modificaram-se no decorrer da carreira? Há uma uniformidade na carreira docente? Tais provocações reportam aos estudos sobre o desenvolvimento profissional, desde o ingresso do estudante na formação inicial, perpassando pelos diferentes momentos da carreira e chegando aos estágios de desvinculação do ambiente de trabalho.

No desenvolvimento profissional, o docente agrega uma gama de expectativas, perspectivas e valores que auxiliam na definição de sua identidade profissional. Contudo, estes fatores não se apresentam dissociados de problemáticas e de enfrentamentos decorrentes do processo de socialização profissional. Neste sentido, vislumbra-se a carreira docente composta por fases, ciclos ou estágios que apresentam características distintas (HUBERMAN, 2000; NASCIMENTO; GRAÇA, 1998; GONÇALVES, 2000; STROOT, 1996; BARONE, 1996). Gonçalves (2000) comenta que o percurso profissional está centrado em dois planos de análise: o desenvolvimento profissional e a construção da identidade profissional. Além disso, o percurso profissional resulta da ação conjunta de três processos de desenvolvimento, que são o processo de crescimento pessoal, o processo de aquisição de competências e eficácias no ensino e o processo de socialização profissional.

Um dos modelos mais referenciado sobre os ciclos de vida profissional de docentes é aquele elaborado por Huberman (2000), cuja classificação foi construída a partir da leitura e análise de estudos empíricos. A sistematização considera os anos de docência dos professores e apresenta algumas características próprias de cada fase vivenciada durante o percurso profissional: fase de entrada na carreira ( 1 a 3 anos de docência), fase de estabilização ( 4 a 6 anos), fase de diversificação ( 7 a 25 anos), fase de serenidade ( 25 a 35 anos) e fase de desinvestimento (mais de 35 anos de docência).

Ao investigarem a carreira docente de professores portugueses de Educação Física, Nascimento e Graça (1998) buscaram estabelecer uma classificação que fosse mais coerente com os anos de docência naquele país, apresentando a fase de entrada ou sobrevivência ( 0 a 3 anos de docência), a fase de consolidação (4 a 6 anos), a fase de diversificação ou renovação ( 7 a 19 anos) e a fase da maturidade ou

Movimento, Porto Alegre, v. 15, n. 01, p. 25-49, janeiro/março de 2009. 
estabilização (20 a 35 anos de docência). De forma semelhante e a partir de estudo com professoras de ensino primário, Gonçalves (2000) descreve a trajetória profissional dos professores como "etapas da carreira", esboçando um perfil para cada uma delas: início (1 a 4 anos de docência), estabilidade (5 a 7 anos), divergência ( 8 a 24 anos), serenidade e renovação do interesse (15-20/25 anos) e desencanto (25 a 40 anos). O modelo de socialização profissional foi empregado por Stroot (1996) para distinguir quatro estágios de desenvolvimento profissional: sobrevivência, consolidação, renovação e maturidade.

$\mathrm{Na}$ tentativa de identificar as características de cada fase e suas determinantes, diferentes abordagens metodológicas têm sido recomendadas, principalmente a realização de estudos longitudinais ou de corte transversal. Nas discussões atuais sobre a construção da carreira destaca-se a importância de estudos sobre as histórias de vida dos docentes, especialmente aqueles que proporcionem um olhar mais significativo em relação às suas vidas, ou seja, que busquem "dar voz e vez ao professor" (NÓVOA, 2000; GOODSON, 2000). Além das investigações ressaltarem as experiênciais vivenciadas pelos docentes em seu cotidiano escolar (JESUS; SANTOS, 2004), os estudos sobre a história de vida docente esclarecem experiências, acontecimentos, trajetórias e relações concretas vivenciadas em um percurco profissional, normalmente significativas na construção pessoal e profissional do sujeito (RÖESCH, 2003; COSTA; GONÇALVES, 2006).

A reflexão da vida profissional, em diferentes momentos da carreira docente, torna-se necessária porque nem todos professores apresentam o mesmo ritmo de trabalho e nem passam pelas mesmas fases ou ciclos de desenvolvimento. De fato, há fatores de ordem social, afetiva e econômica que interferem diretamente no desenvolvimento da carreira, cuja análise de tais fatores pode auxiliar na compreensão do nível de desempenho de cada professor (GONÇALVES; PASSOS, 2004).

Nesta perspectiva, o objetivo desta investigação foi analisar a história de vida de professores de Educação Física que se encontram em diferentes fases da carreira profissional, de modo a identificar as escolhas, perspectivas e trajetórias vivenciadas.

Movimento, Porto Alegre, v. 15, n. 01, p. 25-49, janeiro/março de 2009. 


\section{Procedimentos Metodológicos}

Esta pesquisa caracteriza-se como estudos de caso, com ênfase nas histórias de vida de professores de Educação Física que se encontravam em distintos momentos na carreira docente. A opção por esta abordagem deu-se por entender que somente analisando a biografia, tanto pessoal como profissional de cada sujeito, pode-se refletir e aprofundar sobre as diferentes fases da carreira.

As investigações sobre as histórias de vida resultam da vontade de produzir um novo tipo de conhecimento, que procura aproximar as realidades educativas com o quotidiano dos professores. Assim, a qualidade das abordagens autobiográficas reside na possibilidade de conjugar diversos olhares, de construir uma compreensão multifacetada e de produzir conhecimentos que se situam num entrosamento de vários saberes (NÓVOA, 2000). O respeito pelo autobiográfico é apenas um dos aspectos da relação que permite ouvir a voz do professor, ouvir o que este tem a dizer, respeitando e tratando rigorosamente as informações introduzidas nas narrativas, que são invioláveis e somente podem ser dispensadas após prova rigorosa em relação à sua irrelevância e redundância (GOODSON, 2000).

Nesta pesquisa, foram investigados quatro professores de Educação Física atuantes na realidade escolar. Os participantes foram escolhidos a partir dos anos de docência, conforme a proposta desenvolvida por Nascimento; Graça (1998), em quatro fases de desenvolvimento profissional: entrada, consolidação, diversificação e estabilização. Os professores foram caracterizados da seguinte forma:

- A professora da fase de entrada na carreira concluiu a formação inicial em Educação Física no ano de 2006, numa universidade privada, atua como docente em duas escolas particulares e está finalizando o curso de especialização;

- O professor da fase de consolidação concluiu o curso de Educação Física em 2002, numa universidade comunitária e atua na educação básica na rede municipal de educação e em escolhinhas esportivas;

Movimento, Porto Alegre, v. 15, n. 01, p. 25-49, janeiro/março de 2009. 
- A professora da fase de diversificação finalizou a sua formação inicial em 1988, numa universidade federal, possui especialização e atua na educação básica em uma escola particular;

- O professor da fase de estabilização atua como professor efetivo na rede municipal de educação, também possui especialização e concluiu em 1980 o curso de Educação Física numa universidade estadual.

Na coleta de dados foi utilizado um roteiro de entrevista semiestruturada, cujos temas geradores foram abordados a partir das falas dos participantes. As entrevistas foram realizadas individualmente com cada um dos participantes, a partir da assinatura do Termo de Consentimento Livre e Esclarecido. Todas as entrevistas foram gravadas, com o consentimento do participante, sendo posteriormente transcritas e entregues para cada entrevistado, que tinha a liberdade para alterar o seu conteúdo da maneira que considerasse necessário. Esse procedimento teve a "finalidade de validar o seu conteúdo" e de elevar o "nível de confiabilidade do estudo" (NEGRINE, 1999, p. 78).

A técnica da narrativa foi empregada na análise dos dados, a qual concentrou-se na análise de uma história contada cronologicamente, conforme Garson (2002), procurando enfocar o modo como os elementos são seqüienciados e o porquê da avaliação diferenciada de alguns elementos, nomeadamente como o passado (motivo de escolha profissional) espelha as percepções do presente; como o presente espelha percepções do passado (acontecimentos marcantes - trajetória docente) e como ambos espelham percepções do futuro. Neste contexto, Bueno (2002), Costa; Gonçalves (2006), Huberman (2000) e Wittizorescki et al. (2006) argumentam que as narrativas de professores representam uma possibilidade de produção de conhecimentos mais próximos das realidades educativas e do cotidiano dos professores.

\section{RESULTADOS E discussões}

A partir dos relatos emitidos encontrou-se informações que reportaram à história de vida profissional de cada sujeito e, ao mesmo

Movimento, Porto Alegre, v. 15, n. 01, p. 25-49, janeiro/março de 2009. 
tempo, relacionou-se as escolhas, as trajetórias e as perspectivas em diferentes momentos da carreira docente em que se encontravam. Para melhor operacionalização, as informações de cada professor são apresentadas separadamente, seguidas da análise dos pontos comuns representados em cada fase da carreira.

\subsection{CASO 1: Professora da FASE DE ENTRADA NA CARREIRA}

A dinâmica que orienta as escolhas profissionais considera que a opção pelo magistério, em muitos casos, está relacionada às representações que cada professor tem de si mesmo, de sua inserção no mundo do trabalho e da função social da sua profissão (VALLE, 2003).

Há fatores de ordem social, familiar e pessoal que interferem na escolha de uma profissão. Estes tornam-se preponderantes e decisivos mesmo que, em alguns casos, não correspondem a vontade do futuro professor. Não obstante, a professora da fase de entrada na carreira declarou que o motivo de escolha pela profissão docente estava diretamente relacionado a identificação com a intervenção de sua professora de Educação Física nas séries iniciais do ensino fundamental.

Ao considerar os fatores de influência da profissão docente, Goodson (2000) argumenta que uma característica frequentemente observada nas narrativas é o aparecimento de um professor preferido, o qual influenciou significativamente o docente enquanto estudante. Diferenciando-se desta constatação, no estudo realizado com alunos ingressantes no curso de Educação Física, Botti; Mezzaroba (2007) encontraram que a única influência de escolha pelo curso não considerada pelos investigados foi a relação com os seus professores de Educação Física. Para os autores, este é um registro preocupante e que gera inúmeras reflexões e dúvidas sobre o papel deste profissional em qualquer contexto de sua intervenção.

$\mathrm{O}$ ingresso no mercado de trabalho não foi considerado como um fator determinante e que tenha vindo alterar a escolha profissional desta professora. Assim, caso fosse escolher novamente a profissão, seu motivo de escolha pelo curso universitário estaria vinculado, ainda, à figura da sua professora de Educação Física.

Movimento, Porto Alegre, v. 15, n. 01, p. 25-49, janeiro/março de 2009. 
Ao narrar sua história de vida profissional, a professora destaca como acontecimento marcante de sua trajetória a realização do Trabalho de Conclusão de Curso (TCC), já que este procurou conciliar suas preferências e vivências profissionais. O estudo surgiu de inquietações originadas enquanto estudante-estagiária, o que gerou satisfação e também marcou substancialmente a sua carreira, principalmente por ter sido possível encontrar respostas para algumas perguntas no início de sua caminhada profissional.

Entre os fatos mais marcantes durante o percurso desta professora iniciante na carreira, identifica-se a sua formação para o magistério no ensino médio, porém não atuou como professora em sala de aula. Somente no quarto semestre do curso de Educação Física, quando começou a atuar como estagiária e teve contato direto com a realidade escolar, passou a sentir-se professora.

No final do curso de formação para a docência, Stroot (1996) reconhece que os estudantes são considerados professores e necessitam dominar as competências básicas para a atuação profissional. Assim, perspectiva-se a partir das reformulações curriculares, ocorridas nos últimos anos na realidade brasileira, a criação de ambientes favoráveis à inserção do estudante no contexto real de trabalho ainda durante o curso, proporcionando tanto o encantantamento com a profissão docente quanto o desenvolvimento de competências pedagógicas.

A primeira intervenção profissional da docente iniciante foi em uma escola particular. Inicialmente, trabalhava em turmas de educação infantil e, posteriormente, passou a atuar nas séries iniciais do ensino fundamental, nível de ensino de sua preferência. Como a professora ainda mantém contato com a Universidade, por meio do curso de especialização (o qual encontra-se em fase de conclusão), ela foi a única participante do estudo que mostrou interesse em inserir-se no mercado de trabalho da docência universitária. Apesar do curto espaço de tempo de intervenção profissional na área, visualizase perspectivas de construção de uma carreira no ambiente escolar com ênfase na docência universitária.

Wovimento, Porto Alegre, v. 15, n. 01, p. 25-49, janeiro/março de 2009. 


\subsection{CASO 2: PROFESSOR DA FASE DE CONSOLIDAÇÃO}

Em relação aos motivos pessoais que levaram o professor da fase de consolidação a ingressar no curso de Educação Física, destacam-se as vivências práticas em diferentes modalidades esportivas, em especial o contato com a modalidade de futsal. Embora exista uma gama de fatores que podem influenciar na escolha pelo curso de Educação Física, parece que o esporte é um dos principais agentes de inserção e de motivação para a área. De fato, os estudantes que optam pelos cursos de licenciatura ou de bacharelado em Educação Física, de acordo com Botti; Mezzaroba (2007), possuem um repertório diversificado em atividades físico-esportivo-recreativas e as experiências de sucesso, principalmente no contexto esportivo, têm justificado frequentemente esta opção.

Após a vivência de alguns anos na profissão, o docente destaca que caso fosse novamente optar pela Educação Física, além da experiência esportiva, teria como fator de influência a busca de conhecimentos didáticos e teóricos que pudessem auxiliar na sua intervenção pedagógica.

O professor da fase de consolidação apontou dois acontecimentos marcantes no início da sua carreira: um está relacionado ao contato com a treinamento esportivo vivenciado antes da formação inicial e o outro é referente ao choque na realidade escolar, já que a atuação neste ambiente se difere significativamente do contexto das suas experiências anteriores com as escolinhas de futsal em que atuava. Estudos sobre a fase inicial da carreira docente indicam que a inserção no mercado de trabalho frequentemente resulta em um conflito entre os ideais e a realidade concreta do professor (HUBERMAN, 2000; SHIGUNOV; FARIAS; NASCIMENTO, 2002; MONTEIRO; MIZUKAMI, 2002; GONÇALVES, 2000).

No âmbito escolar o que marcou foi aquele baque que eu tive do treinamento da escolinha para a sala de aula, isso foi um marco que ficou e sempre eu carrego junto, a diferença de estrutura, a diferença de pessoas, de cultura de educação... a realidade aqui onde a gente trabalha é mais barra pesada... $\mathrm{Na}$

Movimento, Porto Alegre, v. 15, n. 01, p. 25-49, janeiro/março de 2009. 
escolinha vai quem quer, quem gosta e quem se dedica. No colégio onde nós trabalhamos é uma obrigação (Professor da fase de consolidação).

No período atual, destaca como marco significativo a gratificação alcançada pelo reconhecido advindo da sociedade, relacionado ao seu trabalho como treinador. A questão da gratificação profissional, do reconhecimento enquanto membro de um contexto favorece o que Huberman (2000) e demais autores caracterizam como estabilização das ações docentes. No contexto escolar, Betti; Mizukami (1997), ao relatarem a história de vida de uma professora de Educação Física aposentada, destacam que esta, após seu ingresso na profissão, indica como ponto marcante de sua carreira o reconhecimento recebido pelo trabalho realizado ao ingressar em uma escola, localizada em uma favela, que implantava naquele momento um novo projeto pedagógico.

$$
\begin{aligned}
& \text { [...] reconhecimento na sociedade [...] tanto que a ação } \\
& \text { social me procurou para fazer um trabalho gratuito } \\
& \text { com crianças da casa lar e eu estou oferecendo isto } \\
& \text { na nossa escolinha. Eles procuravam uma escolinha } \\
& \text { que tivesse um profissional de Educação Física e } \\
& \text { que soubesse mesmo a diferença entre Educação } \\
& \text { Física com o jogo de bola, então fui procurado e isto } \\
& \text { é gratificante (Professor da fase de consolidação). }
\end{aligned}
$$

Percebe-se nos relatos da história de vida deste profissional a grande importância atribuída ao trabalho realizado nas categorias de base no âmbito esportivo (não escolar), o qual influenciou seu desenvolvimento profissional, desde o momento de escolha por esta profissão e que lhe proporciona a participação e conquistas em várias competições.

\subsection{CASO 3: Professora da FASE de DIVERSIFICAÇÃO}

A escolha da Educação Física como campo de atuação profissional pela professora da fase de diversificação refere-se a identificação com as vivências significativas proporcionadas pela sua professora da academia de ginástica. As suas experiências práticas como aluna de academia, na modalidade de dança, desencadeou o interesse pelo ingresso neste curso universitário. A docente também destaca

Movimento, Porto Alegre, v. 15, n. 01, p. 25-49, janeiro/março de 2009. 
que, mesmo após os diversos acontecimentos ocorridos no seu percurso profissional, caso ela fosse atualmente escolher esta profissão, o motivo citado não teria se alterado.

Os modelos profissionais são agentes de motivação à docência em Educação Física. Betti; Mizukami (1997) abordam a biografia de uma professora cuja motivação e interesse pela carreira deu-se pela influência de uma professora do ensino primário, pelo seu modo carinhoso de respeito e atenção aos alunos, bem como pelo estilo de vida ativo dos seus familiares e pelo gosto pela ginástica.

Quanto à construção de sua carreira, a professora relatou que havia formulado alguns planos de trabalho na conclusão do curso universitário, porém, encontrou muitas dificuldades ao ingressar na carreira para realizar os planos como pretendia. O modelo pessoal de intervenção profissional provocou aversões nos alunos, o que a levou, conseqüentemente, a rever e a mudar sua intervenção pedagógica.

[...] sai da universidade cheia de planos de teorias e queria dar teoria para todas as séries... isso não existia sabe, então os alunos estranhavam um pouco. Eu tive assim alguma aversão por parte deles em impor meu estilo de trabalho, e também eu tive que mudar, porque vi que não era o mais certo toda esta questão teórica (Professora da fase de diversificação).

Outro fato que marcou sua carreira foi o reconhecimento do seu trabalho pelo corpo docente da escola, o qual passou ao longo do tempo a valorizar o trabalho desenvolvido e a própria disciplina de Educação Física. Neste momento, a professora encontrava-se na fase de consolidação, denominada também como estabilização por Huberman (2000), caracterizada pela aquisição de responsabilidades e pelos docentes sentirem-se professores aos seus olhos, bem como, na percepção dos demais colegas de escola.

[...] nunca me esqueço, teve uma professora que ela achava, que começou a aprender a respeitar a disciplina quando em uma oportunidade ela me pediu que em minha aula fosse feito determinada coisa e eu disse que não, que em minha aula tinha conteúdos,

Movimento, Porto Alegre, v. 15, n. 01, p. 25-49, janeiro/março de 2009. 
suas atividades sendo desenvolvidas e eu não queria que ela fizesse em minha aula, porque até então a Educação Física para ela era ir lá brincar, hora de qualquer coisa menos aula (Professora da fase de diversificação).

Em sua narrativa, a professora destaca como acontecimento marcante do seu percurso profissional a reestruturação na oferta da disciplina de Educação Física ocorrida na escola em que atua até hoje. A mudança de turmas dividas por gênero para turmas mistas exigiu a adaptação do trabalho pedagógico, principalmente na organização das atividades e os desafios para remediar os problemas de indisciplina.

[...] eu sempre na escola particular, eu tinha condições de trabalhar, os meninos e as meninas separados e eu achava que isso era melhor, era mais fácil, mas agora a gente está trabalhando com as turmas mistas e eu estou gostando, estou achando interessante de trabalhar com meninos, eles são mais competitivos, tem mais animo, mais ímpeto (Professora da fase de diversificação).

A fase de diversificação na carreira é a maior em termos de anos de docência. Além disso, os professores lançam-se em novas propostas curriculares, estão mais envolvidos em equipes pedagógicas, mais motivados e, consequentemente, mais dinâmicos. É reportada a idéia de que os professores buscam os cursos de pós-graduação, assumem cargos de direção e desenvolvem solidificadas ações para a ensino da disciplina no contexto escolar (HUBERMAN, 2000).

\subsection{CAso 4: Professor da fase de ESTABILIZAÇÃo}

Para o professor da fase de estabilização, o fator determinante na escolha da profissão relaciona-se às vivências bem-sucedidas na prática de diferentes modalidades esportivas. No momento da sua escolha profissional, a Educação Física era considerada como segunda opção de formação. Mas, por não ter condições financeiras para realizar o curso desejado e, ao mesmo tempo em que dispunha de habilidades em modalidades esportivas, acabou optando por este campo de intervenção profissional. Shigunov, Farias e Nascimento (2002)

Movimento, Porto Alegre, v. 15, n. 01, p. 25-49, janeiro/março de 2009. 
encontraram também motivos semelhantes entre os professores investigados, os quais se encontravam na fase de consolidação, ou seja, a segunda opção durante a escolha no vestibular e o envolvimento com as atividades físicas e esportivas.

Este docente ressalta que a experiência no cotidiano escolar mudou sua motivação inicial em relação à profissão de professor de Educação Física. Assim, caso hoje tivesse que realizar a opção pela profissão, não escolheria a Educação Física como formação inicial. Mesmo se optasse por esta área, não teria como contexto de intervenção o espaço escolar, mas investiria no treinamento esportivo, na preparação física ou na atuação enquanto personal trainner. A vivência como professor escolar fez com que este docente adquirisse novos conhecimentos e voltasse o seu olhar para outras perspectivas de intervenção. Desta forma, percebe-se que o percurso profissional pode viabilizar desvios da trajetória e o envolvimento em outros espaços que não seja o escolar (HUBERMAN, 2000).

Ao investigar os professores no final da carreira docente, Hopf (2002,p. 91) descreve que "[...] os últimos anos de exercício da docência surgem como um desafio em que uma etapa está sendo concluída, surgindo isto como uma prova para avaliar a capacidade de desvinculação das responsabilidades e do ambiente onde as atividades eram desenvolvidas".

Diversos acontecimentos marcaram a trajetória profissional do professor que se encontra nesta fase final da carreira docente. Este professor narrou seu percurso desde o momento em que prestou concurso público e obteve sua efetivação, até a sua fase atual. No momento inicial da carreira docente, destacou a importância de ter trabalhado com algumas professoras das turmas de séries iniciais, as quais ele considerava ótimas professoras: "[...] então eu tive sorte nesse lado, eu peguei umas professoras também excelentes, então fui desenvolvendo meu trabalho, nesta época a professora também ficava para assistir a aula, para fazer a troca" (Professor da fase de estabilização).

Eventos como estes fortificam a idéia de ser professor. O entusiasmo inicial é uma das características do momento da descoberta

Movimento, Porto Alegre, v. 15, n. 01, p. 25-49, janeiro/março de 2009. 
da carreira, que conforme Huberman (2000, p. 39) é marcada “[...] pela experimentação, a exaltação por estar, finalmente, em situação de responsabilidade [...], por se sentir colega num determinado corpo profissional".

A ampliação da carga horária (não ter mais horas como professor substituto) e sua transferência para outra escola, local em que passou a trabalhar com turmas até oitava série, foram fatos marcantes do seu percurso profissional quando se encontrava na fase de consolidação. Sobre esta fase, a realização de um bom trabalho com as turmas e a participação em competições, foram também mencionados:

[...] a gente ia para competição, só que nós participávamos, porque naquela vez, tinham outros times, os outros times também eram bons e lá a gente não ganhou medalha, só participamos, fomos bem também, mas perdia assim, disputado, disputado" (Professor da fase de estabilização).

A remoção para a escola onde atua até hoje marcou a sua fase de diversificação. A divisão das turmas por gênero gerou algumas dificuldades iniciais, as quais foram superadas gradativamente para proporcionar uma melhor percepção do trabalho realizado neste novo espaço. Ressalta-se também como acontecimentos marcantes de sua trajetória profissional as conquistas em jogos escolares e municipais. A participação nas competições, as condições materiais oferecidas para o desenvolvimento do trabalho, a motivação e o interesse demonstrados pelos alunos em participar das aulas são alguns motivos que foram atribuídos para justificar a sua permanência na escola após o encerramento das atividades.

[...] eu ficava depois da aula, ficava porque gostava, a turma era boa também, os guris eram bons, eles vinham com vontade [...] então essa foi a época que nós ganhamos mais medalhas [...] era por isso que eu ficava depois da aula mesmo, porque as crianças queriam também [...] eu fazia uma preparação física e coletivo, arrumava uma turma da comunidade para jogar com eles, turma para ficar mais forte (Professor da fase de estabilização).

Movimento, Porto Alegre, v. 15, n. 01, p. 25-49, janeiro/março de 2009. 
O professor lamenta a falta de valorização das conquistas esportivas pelos demais membros da comunidade escolar. Os troféus conquistados naquele período, e que fazem parte da história da escola, hoje estão quase todos quebrados. Como forma de preservá-los, o professor solicitou à direção o transporte dos mesmos para sua casa.

A violência escolar, o desrespeito dos alunos para com os docentes, o medo de dirigirem-se às escolas para desempenharem suas funções são fatos que têm marcado o momento atual da carreira docente.

[...] agora a violência está ruim, a violência está batendo na porta de todas as escolas [...] e o que a gente estava vendo nas grandes metrópoles, está batendo agora aqui [...] desrespeito, se você não for um cara durão mesmo, assim disciplinador, eles pintam e bordam, eles tão xingando todo mundo, tão ameaçando já os professores. Aqui já ameaçaram também [...] o professor não ficou nem uma semana e foi embora (Professor da fase de estabilização).

As declarações deste professor revelam alguns sentimentos de amargura e ressentimentos que também foram observados no estudo de Betti; Mizukami (1997). As principais reclamações da fase próxima ao final da carreira dizem respeito ao elevado número de alunos nas turmas, a falta de material adequado e suficiente e os problemas de indisciplina das crianças e jovens, o que tem justificado a vivência de uma fase de conservadorismo.

A riqueza de informações apresentadas permitiu a identificação das fases marcantes e acontecimentos que resultaram no percurso de ser professor, refletindo múltiplas dimensões, conforme Hopf (2002), nos aspectos pessoais, profissionais e contextuais. Além disso, a narrativa da história de vida do professor da fase de estabilização permitiu identificar determinado ressentimento com a política educacional dos governos municipal, estadual e federal, os quais não têm demonstrado a necessária valorização para com sua categoria profissional e não oferecem condições estruturais, materiais e financeiras para possibilitar a realização de um trabalho mais condizente. O professor denuncia a falta de maior dedicação dos colegas mais jovens

Movimento, Porto Alegre, v. 15, n. 01, p. 25-49, janeiro/março de 2009. 
que estão chegando às escolas, os quais deveriam trazer novidades, mas têm demonstrado apenas a vontade de encerrar logo as aulas para sair rapidamente da escola.

Na literatura consultada da área, Lapo; Bueno (2003) comentam as insistentes reclamações dos professoes quanto à impossibilidade de participarem das decisões sobre o rumo do ensino, ao excesso de burocracia e à falta de apoio e reconhecimento do trabalho por parte das instâncias superiores do sistema educacional, o controle do trabalho do professor, a escassez de recursos materiais, a falta de apoio técnicopedagógico e a falta de incentivo ao aprimoramento profissional. Da mesma forma, Huberman (2000) destaca entre as facetas que caraterizam a passagem dos professores para a fase final de suas carreiras, as reclamações constantes da evolução dos alunos (menos disciplinados, motivados etc.), da atitude para com o ensino, da política educacional (confusa, sem orientação clara etc.) e dos colegas mais jovens (menos sérios, empenhados etc.).

Um aspecto a destacar é que, conforme Hopf e Canfield (2001), a fase de estabilização na carreira parece ocorrer de forma diferenciada entre os professores universitários, onde a idéia de crise e abandono da carreira não é permeada. As autoras ressaltam que os professores universitários continuam demonstrando interesse e entusiasmo pelo ensino, apesar de estarem em estágio final de suas carreiras. A aposentadoria, que poderia representar um "desinvestimento amargo", surge como um desafio, o início de uma nova fase em suas carreiras profissionais. Esta situação é apontada por se tratar de professores universitários que possuem uma valorização diferenciada do que a carreira docente escolar. Além de salários mais elevados, as condições estruturais e a percepção dos alunos quanto a formação têm possibilitado um maior contentamento com carreira docente universitária.

\subsection{TRAJETÓRIAS COMUNS}

Na tentativa de identificar o nível de associação nas trajetórias profissionais dos professores envolvidos no estudo, selecionou-se os pontos comuns apresentados nas diferentes fases da carreira docente (Quadro 1).

Movimento, Porto Alegre, v. 15, n. 01, p. 25-49, janeiro/março de 2009. 


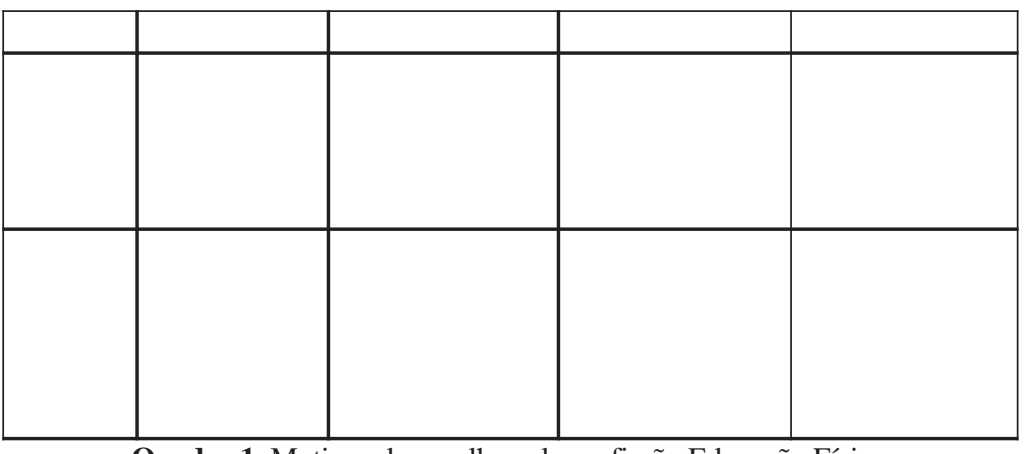

Quadro 1. Motivos de escolha pela profissão Educação Física

Os motivos de escolha pela Educação Física sofrem alterações em distintos momentos de formação, onde a identificação com os primeiros professores e a prática de modalidades esportivas foram os fatores implicados. Enquanto a experiência da prática de modalidades esportivas foi destacada pelos professores, a identificação com uma professora foi demarcada pelas professoras. Entre os docentes investigados, destaca-se que o professor da fase de estabilização foi o único a informar que a Educação Física não influenciou na sua escolha profissional. Além disso, foi o único a indicar que, se hoje tivesse de fazer novamente a sua opção na formação inicial, não teria a Educação Física como primeira opção no vestibular.

As evidências encontradas permitiram identificar que, ao longo da carreira docente, os professores podem manifestar posicionamentos diferenciados aos seus referenciais iniciais, o que pode ser extremamente positivo. Contudo, os professores das fases de entrada, consolidação e diversificação ainda manteriam os mesmos motivos de escolha, sendo que o professor da fase de consolidação apontou outros motivos que seriam incorporados aos anteriores.

Nas investigações sobre a escolha da profissão docente, Vale (2006) comenta que frequentemente recorre aos conceitos de dom e vocação para explicar o ingresso no magistério, bem como para justificar os projetos profissionais vislumbrados. Neste contexto, o estudo realizado por Almeida e Fensterseifer (2007), com professoras de Educação Física, apresentou indicações diferenciadas da escolha

Movimento, Porto Alegre, v. 15, n. 01, p. 25-49, janeiro/março de 2009. 
de ser docente daquelas encontradas na presente investigação. Os fatores de motivação para o ingresso nesta profissão foram o dom e a necessidade de contribuir com um novo referencial para a disciplina, justificados pela falta de motivação que uma das professoras vivenciou quando participou das aulas de Educação Física na escola.

A partir do tempo de atuação na carreira docente e das experiências acumuladas, os professores investigados apontaram alguns fatos ou acontecimentos marcantes na sua trajetória profissional, tanto no momento atual quanto nas fases anteriores (Quadro 2).

$\mathrm{O}$ choque com a realidade foi elemento comum na entrada da carreira docente entre os professores que se encontravam nas fases de consolidação e diversificação. Por outro lado, os professores das fases de entrada e estabilização destacaram aspectos positivos quando do ingresso na carreira docente, especialmente a satisfação em atuar com alguns colegas experientes e a própria efetivação no magistério.

Os aspectos em comum vivenciados pelos professores na fase de entrada são identificados como os estágios de sobrevivência e de descoberta destacados por Huberman (2000) e Gonçalves (2000). O estágio de sobrevivência representa a confrontação inicial da atividade docente com a complexidade da situação profissional, a distância entre os ideais e a realidade da sala de aula, tais como, o primeiro contato com os alunos, os materiais didáticos inadequados e a preocupação consigo próprio. Por outro lado, o estágio de descoberta traduz o entusiasmo inicial, a experimentação, a exaltação pela situação de responsabilidade e inserção em um corpo profissional, enfim, a descoberta de um mundo novo que se apresenta.

O reconhecimento profissional, tanto pelo corpo docente como pela comunidade escolar, foi o fato marcante da fase de consolidação dos professores investigados. A valorização da intervenção profissional parece ter resultado das atividades realizadas na disciplina de Educação Física e no treinamento esportivo. Além de permitir uma maior visibilidade à Educação Física na escola, o desempenho profissional possibilitou a ocorrência de sucesso em competições esportivas escolares, proporcionando, em alguns casos, a ampliação da carga horária de trabalho.

Movimento, Porto Alegre, v. 15, n. 01, p. 25-49, janeiro/março de 2009. 
A fase de consolidação destacada por Nascimento e Graça (1998), também denominada de estabilização por Huberman (2000) e Gonçalves (2000), é caracterizada por alguns dos elementos identificados na trajetória dos professores investigados, como o sentimento de maior segurança e confiança, a gestão do processo de ensinoaprendizagem, a satisfação e o gosto pelo ensino. Para alguns docentes este é um estágio de afirmação perante os colegas mais experientes e as autoridades escolares, precedendo ou acompanhando um sentimento de competência pedagógica crescente.

Entre os aspectos comuns apontados na fase de diversificação, os professores investigados destacaram a extinção das turmas separadas por gênero em favor da oferta de turmas mistas na disciplina de Educação Física. Esta constatação remete a explanação de Costa et al. (2004) e Nascimento; Graça (1998), os quais comentam que a trajetória docente não é afetada somente por experiências pessoais, mas também por influências organizacionais.

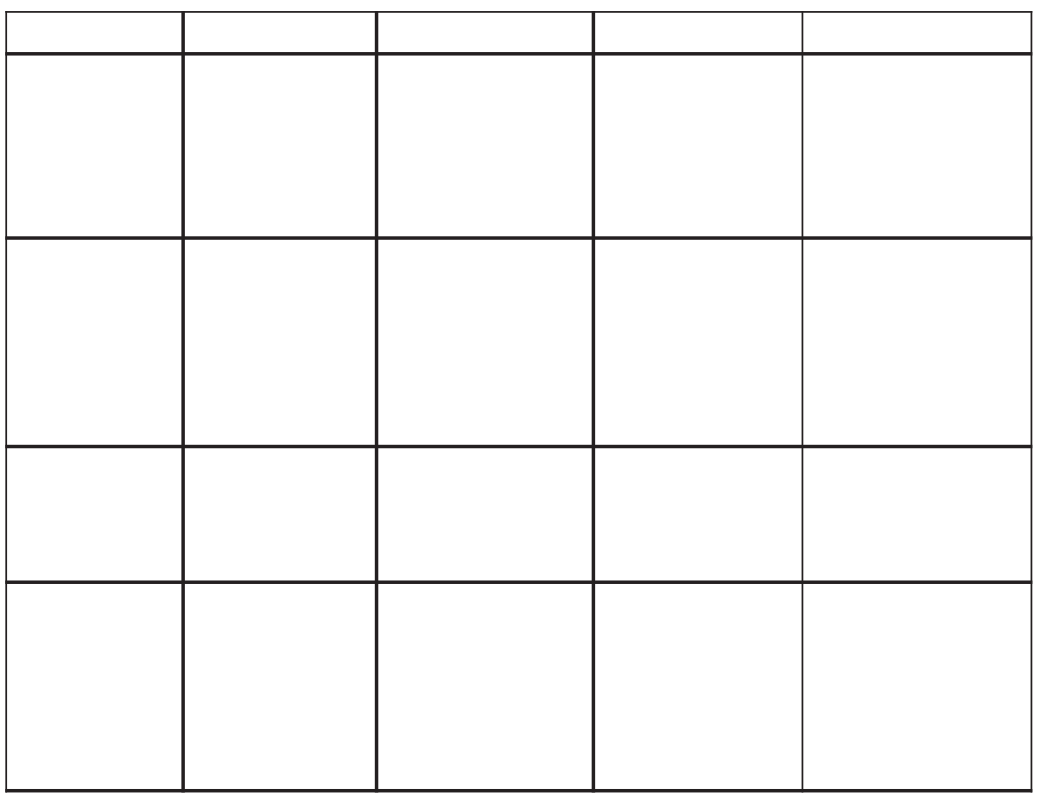

Quadro 2. Fatos ou acontecimentos marcantes na trajetória profissional

Movimento, Porto Alegre, v. 15, n. 01, p. 25-49, janeiro/março de 2009. 
Ao estabelecerem a fase de diversificação como a mais abrangente em anos de docência, Gonçalves (2000), Huberman (2000) e Nascimento; Graça (1998) ressaltam que esta apresenta dois caminhos a serem percorridos. Dependendo de como cada professor constrói a sua carreira, ela poderá oscilar entre uma grande motivação, entusiasmo, diversificação das atividades e dos cargos administrativos almejados, como também por uma forte tendência ao questionamento da rotina de sala de aula, vivência de crises, frustrações com as experiências cotidianas, cansaço e saturação. Neste contexto, observou-se que o professor da fase de estabilização quando se encontrava na fase anterior a atual, ou seja, na fase de diversificação, relatou estar satisfeito e estusiasmado com o trabalho desenvolvido naquele momento.

$\mathrm{O}$ único professor que apresentou fatos marcantes em todas as fases do desenvolvimento profissional foi aquele que se encontrava na fase de estabilização. Embora tenha revelado grande satisfação com o trabalho desenvolvido no cotidiano escolar nas três fases anteriores, na fase atual de sua profissão demonstrou ressentimento com as atitudes de alunos, colegas e com a política educacional, fatores que provavelmente influenciaram a não expressão do sentimento de satisfação com a realização do seu trabalho neste momento.

Em relação aos últimos anos de docência, fase em que os professores se encaminham para a aposentadoria, os professores podem apresentar tanto uma maior serenidade, confiança, entusiasmo quanto uma maior rigidez e dogmatismo, decaindo os níveis de ambição e de investimento, demonstrando cansaço, impaciência e saturação, com queixas freqüentes em relação aos alunos, aos colegas mais jovens e às políticas educacionais; além de consagrarem mais tempo para si e aos interesses exteriores à escola (GONÇALVES, 2000; HUBERMAN, 2000; NASCIMENTO; GRAÇA, 1998).

\section{Considerações FINAIS}

A preocupação em investigar a história de vida profissional de professores de Educação Física permitiu encontrar, ao mesmo tempo, diferenças e similaridades nas escolhas, trajetórias, fatos e acontecimentos vivenciados pelos docentes. Apesar das formações iniciais

Wovimento, Porto Alegre, v. 15, n. 01, p. 25-49, janeiro/março de 2009. 
terem sido cursadas em momentos distintos, as intervenções profissionais realizadas em contextos de atuação diferenciados (escolas públicas e privadas) e as especificidades da história de vida pessoal de cada professor, a abordagem empregada permitiu detectar muitos pontos em comuns na trajetória da carreira docente.

Ao longo deste estudo foi possível descrever quatro histórias, cada uma com características e significados próprios. Além disso, a abordagem das histórias de vida auxiliou na compreensão das fases de desenvolvimento profissional, possibilitando a análise pormenorizada dos mais variados acontecimentos de uma carreira profissional. Assim, acredita-se que foi possível superar o caráter de generalidade que tem marcado os modelos de investigação frequentemente empregados nesta área, os quais têm dificultado a distinção de cada momento da carreira e inviabilizado a busca de questionamentos e maiores esclarecimentos em situações que parecem ser simples na carreira docente, mas que desencadeiam fatores determinantes aos fatos marcantes.

A realização de estudos mais aprofundados sobre as histórias de vida torna-se relevante no momento atual, principalmente para desvendar as crenças, os valores, as competências, a identidade profissional e a relação estabelecida pelo docente com a sua profissão, bem como para auxiliar na sistematização dos anos de docência nas fases de desenvolvimento profissional de professores de Educação Física no Brasil.

Movimento, Porto Alegre, v. 15, n. 01, p. 25-49, janeiro/março de 2009. 


\begin{abstract}
Construction of the Educational Career in Physical Education: choices, paths and perspectives

Abstract: The objective of this investigation was to analyze the history of Physical Education teachers' life, trying to identify the choices, the perspectives and the lived paths. Four teachers participated in the study; they are in different phases of the educational career (entrance, consolidation, diversification and stabilization). In the collect of the information the semistructured interview was used. The technique of the narrative was used in the analysis of the data. The evidences of the study confirm that teachers, even with formations accomplished in different moments and acting in different contexts, they present common points in their professional paths, respected the specificities of each teacher's personal history.

Keywords: Professional role. Faculty. Physical Education. Career Mobility. Case studies.
\end{abstract}

Construcción de la Carrera Docente de Educación Física: decisiones, trayectorias y perspectivas

Resumen: El objetivo de esta investigación fue analizar la biografía de los profesores de Educación Física, intentando identificar sus decisiones, las perspectivas y las trayectorias profesionales vividas. Participaron del estudio cuatro profesores que se encontraban en diferentes fases de su carrera docente (inicio, consolidación, diversificación y estabilidad). En la recogida de las informaciones fue utilizada la entrevista semi-estructurada y la técnica de la narrativa fue empleada en el análisis de los datos. Las evidencias del estudio confirman que los docentes, aún con una formación conseguida en unos momentos diferentes y que actúan en contextos diferenciados, presentan puntos comunes en sus trayectorias profesionales, respetando las situaciones especiales de la historia personal de cada profesor.

Palabras-clave: Rol profesional. Docentes. Educación Física. Movilidad Laboral. Estúdios de casos.

Movimento, Porto Alegre, v. 15, n. 01, p. 25-49, janeiro/março de 2009. 


\section{REFERÊNCIAS}

ALMEIDA, L.; FENSTERSEIFER, P.E. Professoras de Educação Física: duas histórias, um só destino. Movimento, Porto Alegre, v. 13, n. 2, p. 13-35, maio/ago., 2007.

BARONE, T. et al. A future for teacher education: developing a strong sense of profissionalism. In: SIKULA, J.; BUTTEY, T, J.; GUYTON, E. (Org.) Handbook of research on teacher education. New York: Macmillan, 1996. p. 1118-1149.

BENITES, L. C.; SOUZA NETO, S. Educação Física e formação profissional. Revista Digital EFDeportes, Buenos Aires, v. 10, n. 81, fev. 2005. Disponível em: <http:// www.efdeportes.com/revista digital>. Acesso em: 22 mar. 2007.

BETTI, I. C. R.; MIZUKAMI, M. G. N. História de vida: trajetória de uma professora de Educação Física. Motriz, Rio Claro, v. 3, n. 2, p. 108-115, dez. 1997.

BOTTI, M.; MEZZAROBA, C. Relação entre as experiências anteriores e a escolha do curso na formação profissional em Educação Física. Revista da Educação Física, Maringá, v. 18, supl, p. 217-219, 2007.

BUENO, B. O. O método autobiográfico e os estudos com histórias de vida de professores: a questão da subjetividade. Educação e Pesquisa, São Paulo, v. 28, n. 1, p. 11-30, jan./jun. 2002.

COSTA, L. C. A. et al. Potencialidades e necessidades profissionais em Educação Física. Revista da Educação Física, Maringá, v. 15, n. 1, p. 17-23, 1ํㅗㅇ 2004.

COSTA, R. A. B.; GONÇALVES, T. O. Histórias de vidas de professores: apontamentos teóricos. Revista Espaço Acadêmico, Maringá, v. 6, n. 64, set, 2006. Disponível em: <http://www.espacoacademico.com.br/064/64costa.htm\#_ftn1>. Acesso em: 20 jul.2007.

GARSON, G. D. Quantitative Research in Public Administration. 2002. Disponível em: <http://www2.chass.ncsu.edu/garson/pa765/narrativ.htm>. Acesso em: 10 jun. 2007.

GONÇALVES, J. A. M. A carreira das professoras do ensino primário. In: NÓVOA, A. (Org). Vidas de professores. 2. ed. Porto: Porto Editora, 2000. p. 141-169.

GONÇALVES, L. R.; PASSOS, S. R. M. M. D. Processo de desenvolvimento profissional do professor - educação continuada. PARADOXA: Projetivas Múltiplas em Educação, São Gonçalo, v. 10, n. 17, p. 45-56, 2004.

GOODSON, I. F. Dar voz ao professor: as histórias de vida dos professores e o seu desenvolvimento profissional. In: NÓVOA, A. (Org.). Vidas de professores. 2. ed. Porto: Porto Editora, 2000. p. 63-78.

HOPF, A. C. O.; CANFIELD, M. S. Profissão docente: estudo da trajetória de professores universitários de Educação Física. Kinesis, Santa Maria, n. 24, p. 49-71, 2001.

Movimento, Porto Alegre, v. 15, n. 01, p. 25-49, janeiro/março de 2009. 
HOPF, A. C. O. Fico ou vou embora? - Os sentimentos expressos por professores diante da aposentadoria. Revista da Educação Física, Maringá, v. 13. n. 2 , p. 81-88, 2. sem. 2002.

HUBERMAN, M. O ciclo de vida profissional dos professores. In: NÓVOA, A. (Org). Vidas de professores. 2. ed. Porto: Porto Editora, 2000. p. 31-61.

JESUS, S. N.; SANTOS, J. C. V. Desenvolvimento profissional e motivação dos professores. Educação, Porto Alegre, n. 1, p. 39-58, jan-abril, 2004.

LAPO, F. R.; BUENO, B. O. Professores, desencanto com a profissão e abandono do magistério. Cadernos de Pesquisa, São Paulo, n. 118, p. 65-88, mar. 2003.

MARTÍNEZ, J. C. M. Formacion del profesorado de secundaria. Estudios Pedagógicos, Valdivia, n. 26, p. 107-117, 2000.

MONTEIRO, F. M. A.; MIZUKANI, M. G. N. Professoras das séries iniciais do ensino fundamental: percursos e processos de formação. In: REALI, A. M.M. R.; MIZUKAMI, G. N. (Org.). Formação de professores: práticas pedagógicas e escola. São Carlos: EdUFSCar, 2002. p. 175-201.

NASCIMENTO, J. V.; GRAÇA, A. A evolução da percepção de competência profissional de professores de Educação Física ao longo de sua carreira docente. In: CONGRESO DE EDUCACIÓN FÍSICA E CIENCIAS DO DEPORTE DOS PAÍSES DE LÍNGUA PORTUGUESA. CONGRESO GALEGO DE EDUCACIÓN FÍSICA, Porto, 1998. Anais... Porto: Universidade do Porto, 1998.

NEGRINE, A. Instrumentos de coleta de informações na pesquisa qualitativa. In: MOLINA NETO, V.; TRIVIÑOS, A. N. S. (Org.). A pesquisa qualitativa na Educação Física: alternativas metodológicas. Porto Alegre: Ed. Universidade UFRGS: Sulina, 1999. p. 61-94.

NÓVOA, A.. Os professores e as histórias da sua vida. In: NÓVOA, A. (Org.). Vidas de professores. 2. ed. Porto: Porto Editora, 2000. p. 11-30.

PRADO, J. M. Representação socioeconômica e expectativas sobre o mercado de trabalho dos acadêmicos do curso de Educação Física da UNOPAR - Arapongas 2006. Revista da Educação Física, Maringá, v. 18, supl. p. 213- 216, 2007.

RÖESCH, I. C. C. Ressignificando a formação docente: um estudo sobre as histórias de vida dos afro-brasileiros. In: SEMINÁRIO INTERNACIONAL EDUCAÇÃO INTERCULTURAL, GÊNERO E MOVIMENTOS SOCIAIS, 2, 2003. Florianópolis. Anais... Florianópolis, [s. n], 2003. 1 CD-ROM

SHIGUNOV, V.; FARIAS, G. O.; NASCIMENTO, J. V. O percurso profissional dos professores de Educação Física nas escolas. In: SHIGUNOV, V.; SHIGUNOV NETO, A. (Orgs.). Educação Física: conhecimento teórico $X$ prática pedagógica. Porto Alegre: Mediação, 2002. p. 103-152.

SILVA, M. C. M. O primeiro ano de docência: o choque com a realidade. In: ESTRELA, M. T. (Org.). Viver e construir a profissão docente. Porto: Porto Editora, 1997. p. $51-80$.

Movimento, Porto Alegre, v. 15, n. 01, p. 25-49, janeiro/março de 2009. 
STROOT, S. Organizational socialization: factors impacting beginning teachers. In: SILVERMAN, S. J.; ENNIS, C. (Orgs.). Student learning in Physical Education. Champaign: Human Kinetics, 1996. p. 339-365.

TARDIF, M. Saberes profissionais dos professores e conhecimentos universitários: elementos para uma epistemologia da prática profissional dos professores e suas conseqüências em relação à formação para o magistério. Revista Brasileira de Educação, Rio de Janeiro, n.13, p. 5-13, jan./abr. 2000.

VALLE, I. R. A era da profissionalização: formação e socialização profissional do corpo docente de 1ํㅡ a 4ª série. Florianópolis: Cidade Futura, 2003.

VALLE, I. R. Carreira do magistério: uma escolha profissional deliberada? Revista Brasileira de Estudos Pedagógicos, Brasília, v. 87, n. 216, p. 178-187, maio/ ago. 2006.

WITTIZORECKI, E. S. et al. Pesquisar exige interrogar-se: a narrativa como estratégia de pesquisa e de formação do(a) pesquisador(a). Movimento, Porto Alegre, v. 12, n. 2, p. 9-33, mai/ago. 2006. 